\title{
Social Responsibility for Labor Productivity in Companies
}

\author{
Osmiriam Campuzano $^{\# 1}$, Raúl J. Martelo ${ }^{* 2}$, Diofanor Acevedo ${ }^{* 3}$ \\ ${ }^{*}$ Department of extension, University of La Guajira, Fonseca, La Guajira, Colombia \\ ${ }^{1}$ oscadi197@gmail.com \\ *Faculty of Engineering, Faculty of Economics Sciences, \\ University of Cartagena, Cartagena, Bolívar, Colombia. \\ 2 rmartelog1@unicartagena.edu.co \\ 3diofanor3000@gmail.com
}

\begin{abstract}
The objective of the research was to determine the relationship of social responsibility with labor productivity in companies. This allows establishing a link that facilitates the identification of flaws in the organization with respect to work performance and its commitment to the welfare of society. For this, questionnaires were applied to 85 workers of the company Quala S.A. of Colombia and the Distribuidora de Consumo Masivo Rave C. A of Venezuela, which were analyzed with the Pearson coefficient. This resulted in a coefficient of $r=0.88$, denoting a strong positive relationship for the variables Social responsibility and Labor production, However, there are problems for companies regarding aspects such as workers' compensation and job stability, and they do not comply with economic, legal, ethical and environmental levels of responsibility.
\end{abstract}

Keyword - Labor performance, Production, Management, Environment, Society

\section{INTRODUCTION}

Companies meet their objectives with an adequate level of management, taking into account factors that influence personnel; which keeps production running for sustainability. This process is considered a measure of the performance of the organization and indicates the efficiency with which it can convert inputs into products, in order to meet market demands and acquire a competitive level [1]. Therefore, companies must seek to have a qualified workforce, which allows them to face the productivity challenges generated by globalization in the business environment [2].

In circumstances where the market is changing, the demand for quality products and services is higher and the competition level is high, the survival of companies is vulnerable [3]. In these cases, management must execute strategies to increase productivity considering labor, in order to establish labor costs, the amount of products or services and limit production time, this is considered as labor productivity [4]. This aspect is essential in companies because it is an index of competitiveness, for which it is necessary to manage it adequately, in order to achieve the greatest benefit in the pursuit of the objectives of the organization.

In this sense, the company must encourage its employees through contributions to society, which generate motivation and attract new interested workforce, in order to increase labor productivity and comply with social responsibility standards [5]. The foregoing leads to the implementation of this social-moral commitment in the areas that complement the organizations, such as the case of [6] where the feasibility of the application of corporate social responsibility strategies is investigated in order to obtain improvements in the accessibility of finance and reduce the limitations generated by the capital restriction. On the other hand, in [7] the relationship between social responsibility and the commercial relationships that companies have is studied, through the development of a framework that allows determining the influence of the social commitment of the suppliers and the clients of the organization.

In other related studies, in [8] a model is proposed that allows analyzing the relationship between corporate social responsibility, identification of the consumer's company, the prestige of the brand and purchase intention, in order to obtain loyalty and improve satisfaction the client's. In addition, in [9] they propose the implementation of corporate social responsibility and its impact on the profitability of a company, which provides a guide that facilitates investment in such social-moral commitment to managers. The referred studies demonstrate the importance of social responsibility in the performance of companies, therefore there is a need to investigate the opinion of employees about the advantages that this can provide, however, there are still sectors where employees do not consider it as a sufficient incentive [10].

Taking into account the above, the objective of the research is to determine the relationship that exists between social responsibility and labor productivity in companies. As a case study, companies from Colombia and Venezuela were chosen, in order to analyze the behavior of these two variables in different regions, which allows promoting the practice of social responsibility in employees to facilitate cooperative and voluntary work. 


\section{Methodology}

This investigation was of a quantitative type, with a non-experimental correlational cross-sectional design; quantitative because they gather and use numerical data [11]; not experimental because variables are determined, which the researcher does not alter [12]; cross-sectional since information is collected only once in time [13]; and correlational because the degree of association between two variables is determined [14].

Based on the foregoing, the established variables are shown in Table 1. Additionally, dimensions and indicators were established in order to quantify Social Responsibility and Labor Productivity.

TABLE I. Variables, dimensions and indicators

\begin{tabular}{|c|c|c|}
\hline Variables & Dimensions & Indicators \\
\hline \multirow{11}{*}{$\begin{array}{c}\text { Social } \\
\text { responsibility }\end{array}$} & \multirow{4}{*}{$\begin{array}{l}\text { Level of social } \\
\text { responsibility }\end{array}$} & Economical \\
\hline & & Legal \\
\hline & & Ethical \\
\hline & & Environmental \\
\hline & \multirow{4}{*}{$\begin{array}{l}\text { Responsible } \\
\text { business } \\
\text { management }\end{array}$} & Product quality \\
\hline & & Strategic processes \\
\hline & & Customer satisfaction \\
\hline & & Customer service \\
\hline & \multirow{3}{*}{$\begin{array}{l}\text { Philanthropic } \\
\text { behavior }\end{array}$} & Social investment \\
\hline & & Social Alliance \\
\hline & & Social care \\
\hline \multirow{7}{*}{$\begin{array}{l}\text { Labor } \\
\text { productivity }\end{array}$} & \multirow{4}{*}{$\begin{array}{l}\text { Motivational } \\
\text { factors }\end{array}$} & Remuneration \\
\hline & & Recognition \\
\hline & & Employment stability \\
\hline & & Training \\
\hline & \multirow{3}{*}{ Production factors } & Physical capital \\
\hline & & Human capital \\
\hline & & Technological capita \\
\hline
\end{tabular}

\section{A. Population and sample}

The population was conformed by personnel of the companies Quala S.A. of Colombia and the Distribuidora de Consumo Masivo Rave C.A. of Venezuela, with 49 and 36 employees respectively, which resulted in a total of 85 people. In addition, a sample was not defined due to the fact that it was possible to access the entire population, for which a population census was applied in order to collect the information necessary for the investigation.

\section{B. Data collection techniques}

A survey and bibliographic review were used to obtain relevant data. The first one was executed through two questionnaires; one to evaluate the Social Responsibility variable, integrated with 33 items, and another to measure Labor Productivity, consisting of 21 items. In addition, the Likert scale was taken into account for the elaboration of the same, where each element had 5 response options with different scores: Always (5), Almost always (4), Sometimes (3), Almost never (2) and Never (1). Regarding the second, it allowed access to alternative information sources such as indexed databases, scientific articles, books, manuscripts, among others.

\section{Validity and reliability of the instrument}

The questionnaires were validated using the expert judgment technique, which was supported by 5 experts in the area, who were responsible for reviewing the questionnaires and expressing their opinions, suggestions and corrections, in order to improve the instruments in question. In the same way, a pilot test was carried out in the company of 10 workers belonging to the company under study, in order to determine the reliability. In addition, the statistical procedure of the Cronbach Alpha coefficient (Formula 1) was used, because it allows to measure the reliability of instruments with a Likert structure. 


$$
\propto=\left[\frac{n}{n-1}\right]\left[1-\frac{\sum_{i=1}^{n} s_{i}^{2}}{s_{t}^{2}}\right]
$$

\section{Wherein:}

$n$ : Number of items that the instrument has

$\alpha$ : Reliability coefficient

$s_{i}{ }^{2}$ : Variance of the scores of each item

$s_{t}{ }^{2}$ : Variance of totals

For which categories and ranks were considered, as shown in Table 2.

TABLE II. Cronbach Alpha coefficient

\begin{tabular}{|c|c|}
\hline Category & Rank \\
\hline Very high & $0.81-1$ \\
\hline High & $0.61-0.80$ \\
\hline Moderate & $0.41-0.60$ \\
\hline Low & $0.21-0.40$ \\
\hline Very low & $0.1-0.2$ \\
\hline
\end{tabular}

Based on what was described, a very high level of reliability was obtained, since the result of the calculation was 0.87 .

\section{Data analysis}

To analyze the data, statistical techniques were used, such as frequency, percentage and arithmetic mean. Similarly, the processed data were tabulated in table, to adapt the understanding of them, taking into account that the surveyed subjects could only select a response option, with a score equivalent to an integer between 1 and 5. On the other hand, a scale was elaborated (Table 3) where the variables, dimensions and proposed indicators are examined, in order to interpret the data.

TABLE III. Scale for the statistical analysis of the average

\begin{tabular}{|c|c|c|}
\hline Level & Interval & Category \\
\hline 5 & $4.24-5.00$ & Very favorable \\
\hline 4 & $3.43-4.23$ & Favorable \\
\hline 3 & $2.62-3.42$ & Moderately favorable \\
\hline 2 & $1.81-2.61$ & Little favorable \\
\hline 1 & $1-1.80$ & Unfavorable \\
\hline
\end{tabular}

Regarding the relationship between the variables, the Pearson correlation coefficient procedure was applied, where the scores reached by each variable are considered (Formula 2).

$$
\partial x y \approx \frac{\sum D x \cdot D y}{\sqrt{\sum D x^{2} \cdot \sum D y^{2}}}
$$

Wherein:

$\partial$ : Correlation coefficient.

$\sum D x . D y:$ Sum of $\mathrm{X}$ and $\mathrm{Y}$

$\sum D x^{2}:$ Sum de $\mathrm{X}^{2}$

$\sum D y^{2}:$ Sum de $\mathrm{Y}^{2}$

In this way, the coefficient obtained with the Pearson procedure can vary between -1 and 1 , therefore the different types of correlation were taken into account, as well as the ranges to which they belong (Table 4). 
TABLE IV. Pearson coefficient

\begin{tabular}{|l|l|}
\hline Type of correlation & Rank \\
\hline Positive perfect & $0.90<\mathrm{X} \leq 1.00$ \\
\hline Strong Positive & $0.75<\mathrm{X} \leq 0.90$ \\
\hline Considerable Positive & $0.50<\mathrm{X} \leq 0.75$ \\
\hline Medium Positive & $0.10<\mathrm{X} \leq 0.50$ \\
\hline Weak Positive & $0.00<\mathrm{X} \leq 0.10$ \\
\hline Does not exist & $\mathrm{X}=0$ \\
\hline Weak Negative & $0.00>\mathrm{X} \geq-0.10$ \\
\hline Medium Negative & $-0.10>\mathrm{X} \geq-0.50$ \\
\hline Considerable Negative & $-0.50>\mathrm{X} \geq-0.75$ \\
\hline Strong Negative & $-0.75>\mathrm{X} \geq-0.90$ \\
\hline Perfect Negative & $-0.90>\mathrm{X} \geq-1.00$ \\
\hline
\end{tabular}

\section{III.RESULTS}

The results of the questionnaires applied to the participating subjects of the Colombian company Quala S.A. and the Venezuelan RAVE C.A., the information collected was tabulated and grouped to perform an analysis. A summary of the data obtained previously was made, with the purpose of contrasting the dedication of the Colombian-Venezuelan companies for the execution of social responsibility. This shows in detail in Table 5.

TABLE V. Summary of the dimension Levels of social responsibility. Colombia-Venezuela

\begin{tabular}{|c|c|c|c|c|}
\hline Indicators & Colombia & Category & Venezuela & Category \\
\hline Economical & 2.73 & Moderately favorable & 2.89 & Moderately favorable \\
\hline Legal & 3.36 & Moderately favorable & 2.89 & Moderately favorable \\
\hline Ethical & 3.37 & Moderately favorable & 3.33 & Moderately favorable \\
\hline Environmental & 3.41 & Moderately favorable & 3.22 & Moderately favorable \\
\hline Averages & 3.22 & Moderately favorable & 3.08 & Moderately favorable \\
\hline
\end{tabular}

From the results obtained in the companies of Colombia and Venezuela it is evident that the behavior of the dimension of social responsibility levels turned out to be similar, because in the companies of both countries in a moderate way they comply with the levels of responsibility concerning economic aspects, legal, ethical and environmental, in order to provide better living conditions, training and professional development.

However, when contrasting these findings with the theory referred to in [15], by pointing out that social responsibility refers to the responsible actions of its members, charitable activities and the organization's commitments to society in general, in a more intense, with those groups or part of the society with which you are most in touch. According to the above, it can be said that social responsibility is a style of being the institution, of each one of the people that make up the institution.

In relation to the results of the analysis of the dimension Responsible business management in companies of Colombia and Venezuela, a summary was made and compared to determine similarities between the management processes carried out in these, this is reflected in Table 6.

TABLE VI. Summary of the dimension Responsible business management. Colombia-Venezuela

\begin{tabular}{|c|c|c|c|c|}
\hline Indicators & Colombia & Category & Venezuela & Category \\
\hline Product quality & 3,44 & favorable & 2,97 & Moderately favorable \\
\hline Strategic processes & 3,24 & Moderately favorable & 3,08 & Moderately favorable \\
\hline Customer satisfaction & 3,46 & favorable & 3,28 & Moderately favorable \\
\hline Customer service & 3,28 & Moderately favorable & 3,17 & Moderately favorable \\
\hline Averages & 3,35 & Moderately favorable & 3,13 & Moderately favorable \\
\hline
\end{tabular}

It can be seen that the averages for companies in Colombia and Venezuela are close, although those in Colombia are slightly higher, indicating that in both companies there is a very similar behavior with respect to the management of social responsibility, through the quality of the product, strategic processes, satisfaction and customer service. 
On this aspect in [16] it is established that responsible management implies a moral behavior, where it is understood that the construction of capacities and values is achieved by others; therefore, in the training process, the conditions of relationships in the workplace must be considered. A company that signals and develops a responsible behavior with workers, suppliers and consumers, can obtain greater productivity of its employees and higher quality of supplies from suppliers.

Regarding the Philanthropic Behavior dimension, the means obtained from the corresponding indicators were compared, in order to determine similarities with respect to the philanthropic behavior of the companies and to define a general result of the evaluated dimension. The foregoing can be evidenced in Table 7.

TABLE VII. Summary of the dimension Philanthropic behavior. Colombia-Venezuela

\begin{tabular}{|c|c|c|c|c|}
\hline Indicators & Colombia & Category & Venezuela & Category \\
\hline Social investment & 2.90 & Moderately favorable & 3.28 & Moderately favorable \\
\hline Social Alliance & 3.08 & Moderately favorable & 3.28 & Moderately favorable \\
\hline Social care & 3.51 & favorable & 3.22 & Moderately favorable \\
\hline Averages & 3.16 & Moderately favorable & 3.26 & Moderately favorable \\
\hline
\end{tabular}

The comparison made of the Colombian and Venezuelan companies, allowed to show that the behavior of both is similar, because they were placed in the same category of Medium favorable, which means that resources are used to meet the needs of the communities surrounding the company, as well as little partnership with the community to share social projects.

In this regard, there is a discrepancy with what is stated in [17] where it is indicated that social investment emphasizes the funds allocated to projects and personnel to promote the reciprocal development between them and society, where the strategy is analyzed that is convenient for both parties. This investment is usually encouraged by the ideal of development and values of social responsibility, in which ethical objectives, environmental and social means and financial objectives are mixed.

On the other hand, the variable Labor productivity according to its dimensions and indicators was analyzed, by grouping the information obtained from the respondents, where the information obtained from the companies in Colombia and Venezuela was compared. Initially the motivational factors dimension was analyzed as shown in Table 8.

TABLE VIII. Summary of the dimension Motivational factors. Colombia-Venezuela

\begin{tabular}{|c|c|c|c|c|}
\hline Indicators & Colombia & Category & Venezuela & Category \\
\hline Remuneration & 3.55 & favorable & 3.52 & Moderately favorable \\
\hline Recognition & 3.16 & Moderately favorable & 3.25 & Moderately favorable \\
\hline Employment stability & 3.37 & favorable & 3.17 & Moderately favorable \\
\hline Training & 3.46 & & 2.89 & \\
\hline Averages & 3.39 & Moderately favorable & 3.21 & Moderately favorable \\
\hline
\end{tabular}

The similarities are observed in the categories that represent the means of respondents' responses, which denotes a favorable remuneration that corresponds to the expectations of the workers. However, they provide little training for employees to develop their skills and do not use forms of recognition to the staff, to achieve better performance, nor is the worker assured of job stability.

The results presented are not entirely consistent with what is established in [18], where it is affirmed that the motivational factors are those that produce lasting effects of satisfaction and increase of productivity in levels of excellence. The term motivation includes feelings of accomplishment, growth and professional recognition, manifested through the exercise of tasks that offer sufficient challenges and meaning to the worker. When the motivational factors are optimal, satisfaction increases substantially, when they are precarious, causing lack of satisfaction.

Then, for the Labor productivity factors dimension, the questionnaire responses were grouped for each indicator and the statistical process was carried out to determine the mean as shown in Table 9.

TABLE IX. Summary of the dimension Motivational factors. Colombia-Venezuela

\begin{tabular}{|c|c|c|c|c|}
\hline Indicators & Colombia & Category & Venezuela & Category \\
\hline Physical capital & 3,92 & Moderately favorable & 4,00 & Moderately favorable \\
\hline Human capital & 3,33 & Moderately favorable & 3,50 & Moderately favorable \\
\hline Technological capital & 3,61 & favorable & 3,60 & Moderately favorable \\
\hline Averages & 3,62 & Moderately favorable & 3,70 & Moderately favorable \\
\hline
\end{tabular}


The averages obtained indicate that the dimension evaluated is favorable for the companies studied, which denotes that they possess physical resources used in the manufacture of products, as well as consider human capital as an important element in the development of the company and have the necessary technological equipment so that their workers carry out their activities properly. The above shows that the company channels its strategies towards the well-being of the workers and of the company itself, in order to obtain optimum performance in its activities.

In this sense, the answers given by the respondents were evaluated according to the Pearson coefficient, which took into account the performed analyzes and the means obtained for each dimension and indicator. The aforementioned produced a value of $\mathrm{r}=0.88$, which evidences the existence of a strong positive relationship between the variables Social responsibility and Labor productivity, indicative of a directly proportional influence between both. For this reason, companies must assume social responsibility as a relevant aspect to achieve greater labor productivity.

\section{IV.CONCLUSION}

Based on the results obtained, it can be concluded that:

1) The relationship between Social Responsibility and Labor Productivity is positive and directly proportional, which is why it should be assumed as an influential factor in performance and competitiveness.

2) Companies have a moderate and similar behavior regarding the management of social responsibility through product quality, strategic processes, satisfaction and customer service.

3) The managers of the companies comply with actions related to social investment, social alliance and social assistance, and invest fewer resources and make alliances to meet the needs of the communities around the company.

4) The companies offer goods and services to the workers to satisfy their needs and provide the adequate living conditions, with training and professional development.

5) It is necessary to reinforce the motivation and generate confidence in the workers of the company, to increase the quality of the work processes.

\section{REFERENCES}

[1] S.K. Ojha, "Management of Productivity Who is Responsible for Unproductiveness?," Journal of General Management Research, vol. 1 , issue 2, pp. 83-98, 2014.

[2] J. Onkelinx, T. S. Manolova and L. F. Edelman, "The human factor: Investments in employee human capital, productivity, and SME internationalization," Journal of International Management, vol. 22, no. 4, pp. 351-364, 2016.

[3] A. Moges, F. Moges, P. Helo, J. Takala and D. J. Powell, "Adoption of quality management practices: An investigation of its relationship with labor productivity for labor-intensive manufacturing companies," Benchmarking: An International Journal, vol. 21, issue 1, pp.77-100, 2014.

[4] H. Agarwal, S. Agrawal and M. Pandey, "A case study on labor productivity," International Research Journal of Engineering and Technology, vol. 3, no. 12, pp. 664-667, 2016.

[5] P. Crifo, and V. D. Forget, “The economics of corporate social responsibility: A firm - level perspective survey," Journal of Economic Surveys, vol. 29, no. 1, pp. 112-130, 2015.

[6] B. Cheng, I. Ioannou and G. Serafeim, "Corporate social responsibility and access to finance," Strategic Management Journal, vol. 35, pp. 1-23, 2014

[7] C. Homburg, M. Stierl and T. Bornemann, "Corporate Social Responsibility in Business-to-Business Markets: How Organizational Customers Account for Supplier Corporate Social Responsibility Engagement,” Journal of Marketing, vol. 77, pp. 54-72, 2013.

[8] M. H. Chen, P. N. Tai and B. H. Chen, "The Relationship among Corporate Social Responsibility, Consumer-Company Identification, Brand Prestige, and Purchase Intention,” International Journal of Marketing Studies, vol. 7, no. 5, pp. 33-40, 2015.

[9] P. Bhardwaj, P. Chatterjee, K. D. Demir and O. Turut, "When and how is corporate social responsibility profitable?," Journal of Business Research, vol. 84, pp. 206-219, 2018.

[10] D. Korschun, C. B. Bhattacharya and S. Swain, "Corporate Social Responsibility, Customer Orientation, and the Job Performance of Frontline Employees," Journal of Marketing, vol. 78, pp. 20-37, 2014.

[11] L. Christensen, R. Burke and L. Turner, Research Methods, Design, and Analysis. Boston: Pearson, 2015.

[12] D. Ary, L. Cheser, C. Sorensen and A. Razavieh, Introduction to Research in education. Belmont: Wadsworth Cengage Learning, 2010.

[13] P. Leavy, Research Design, Quantitative, Qualitative, Mixed Methods, Arts-Based, and Community-Based Participatory Research Approaches. Nueva York: The Guildford Press, 2017.

[14] R. Kumar, Research Methodology a step-by-step guide for beginners. Londres: SAGE Publications, 2011

[15] I. Chiavenato, Recursos Humanos - O capital humano das organizaçoes, 10th edition. Rio de Janeiro: Elsevier. 2009.

[16] P. Hibbert, and A. Cunliffe, "Responsible Management: Engaging Moral Reflexive Practice through Threshold Concepts," Journal of Business Ethics, vol. 127, no. 1, pp.177-188, 2013.

[17] C. McElroy, "Corporate foundations in the mining industry: the relationship between responsible investment and social investment," Journal of Sustainable Finance \& Investment, vol. 2, no. 3-4, pp. 240-256, 2014.

[18] S. Robbins, and T. Judge, Organization Behavior, 15th edition. Mexico: Pearson, 2013. 


\section{AUTHOR PROFILE}

Osmiriam Campuzano Díaz works as extension coordinator at University of La Guajira (Colombia). Mrs. Campuzano completed her magister from Rafael Belloso Chacín University (Venezuela). Mrs. Campuzano completed her undergraduate in Business Administration at the Univerity of La Guajira.

Raúl J. Martelo works as full-time professor at the University of Cartagena (Colombia). Mr. Martelo completed his magister from Industrial University of Santander (Colombia). Mr. Martelo completed his undergraduate in Systems Engineering at the Industrial University of Santander.

Diofanor Acevedo Correa works as full-time professor in the University of Cartagena (Colombia). Dr. Acevedo completed his doctorate from University of Valle (Cali-Colombia). Mr. Acevedo completed his undergraduate in Food Engineering and Pharmaceutical Chemistry at the University of Cartagena. 